Could disadvantaged students' academic achievements be improved through after-school learning and self-efficacy? An empirical study in Taiwan

Chang, I Hsiung

Toko University, Taiwan (elite5931.tw@gmail.com)

Chin, Joseph Meng-Chun

National Chengchi University, Taiwan (mcchin@nccu.edu.tw)

Ching, Gregory S. $\$

Fu Jen Catholic University, Taiwan (gregory_ching@yahoo.com)

Chuang, Ching-Pao

Executive Yuan, Taiwan (ㄹu3368@ev.gov.tw; edu6806@gmail.com

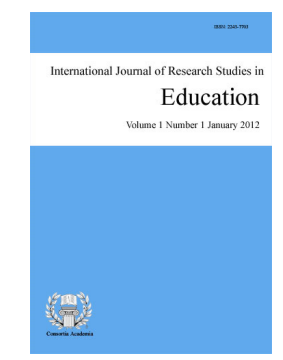

ISSN: 2243-7703 Online ISSN: 2243-7711

OPEN ACCESS

\title{
Abstract
}

Improving the academic achievements of disadvantaged students is one of the most important educational issues for many countries and regions including Taiwan. To achieve the goal, governments and non-governmental organizations in Taiwan have been allocating resources to after-school tutoring and private supplementary tutoring for the disadvantaged middle school students over the years. However, it is still uncertain whether these measures are truly effective. To determine whether disadvantaged students' academic achievement is improved by after-school learning (including private supplementary tutoring and after-school tutoring) and self-efficacy, analysis is accomplished using the "Taiwan Database of Children and Youth in Poverty". Some findings include: 1) nearly half of these disadvantaged students do not attend after-school learning, while their academic achievements are poorer; 2) majority of these students have lower self-efficacies, however their self-efficacies is slightly enhanced by after-school learning; 3) the higher the students' self-efficacies are, the slightly better their academic achievements will be; 4) attending after-school learning seems to have a direct effect on the slight improvement towards the students' academic achievements, furthermore, attending after-school learning can also indirectly affect the slight improvement of students' academic achievements through self-efficacies; and 5) among the different types of after-school learning, private supplementary tutoring is more effective than after-school tutoring in helping disadvantaged students increase their percentage in having better academic achievements. Based on these findings, suggestions are proposed to the education authorities for future references.

Keywords: after-school learning; self-efficacy; academic achievement; structural equation modelling 


\section{Could disadvantaged students' academic achievements be improved through after-school learning and self-efficacy? An empirical study in Taiwan}

\section{Introduction}

\subsection{Theoretical background and Motivation}

Within the concept of social reproduction, children are said to inherit their parent's economic status; moreover, the economic advantages of the offspring of higher social-status families can go considerably beyond the superior education they receive. More important, research has shown that the earnings of poor and rich parents correlate with their offspring' earnings separately (Bowles \& Gintis, 2002), which is actually quite sad. Therefore, the role of "education" should include the opportunity for social mobility such as helping disadvantaged students rise from poverty, instead of just being a tool for dominating thoughts. In other words, the children from disadvantaged families should have a chance of getting free from being trap in the bottom of society, and avoid the vicious circle of social reproduction.

The period of middle school is an important phase in determining whether students have enough basic competencies or not. Hence, it would be quite important to analyze whether the achievement rankings of disadvantaged students on this level is falling behind. As a result, the current study shall focus on disadvantaged middle school students, and the academic achievement (including passing exams and achievement rankings) as one of the primary variables. In addition, although the governments and non-governmental organizations (NGOs) have tried to help disadvantaged students improve their academic achievements through after-school learning; however, the actual effect of these additional efforts are yet to be determine.

The term of "after-school learning" is specified as an integrated concept which includes "private supplementary tutoring", and "after-school tutoring" in this paper. These terms can be distinguished as follows:

Firstly, "private supplementary tutoring" is well known as the "shadow education" in most countries, it aims to provide additional help to students outside of school mainly to prepare for examinations (Bray, 2013; Byun \& Baker, 2015). It is also called "Buxiban", "tutorial education", or "tutorial center" in Taiwan, and it means learning in a private institution or place during after school hours or after office hours for enriching some academic knowledge and skills or devoting to raising their grades on primary subjects (Ministry of Education, 2000). According to the article 6 of the "Supplementary Education Act" of Taiwan, short-term tutorial education may be provided by schools, government organizations, foundations, or private parties; moreover, short-term tutorial centers is divided into two categories: non-academic short-term tutorial centers and academic short-term tutorial centers. In brief, most of the private supplementary tutoring institutions are for profit-seeking.

Secondly, "after-school tutoring" means tutoring during after class hours for passing the examinations in primary school subjects or improving academic achievements (Ministry of Education, Taiwan, 2000). In general, after-school tutoring is a non-profit tutoring which is initiated by a school, a teacher or a non-profit organization. Broadly speaking, some remedial instruction programs may be seen as one of the "after-school tutoring" strategies in Taiwan (Chen, Tzeng, \& Chang, 2015; Li \& Lien, 2010).

Thirdly, with regard to the concept of "after-school learning", Chen (2017) mentioned that after-school mathematics learning activities includes participation in private supplementary tutoring of mathematics or the completion of mathematics homework. Additionally, within the "school-based after-school learning and support programs" implemented by Hong Kong Education Bureau, it supports the participation of disadvantaged students in after-school activities which includes tutorial service, personal development (such as cultural and art activities, sports activities, leadership training, and many others) and skills training. Moreover, after-school 
remedial classes can also be subsidized by the program itself (Hong Kong Education Bureau, 2018; Legislative Council of Hong Kong, 2011). To sum up, within the current study the meaning of "after-school learning" includes private supplementary tutoring and after-school tutoring. In other words, it takes after-school hours for tutoring students in the foundational subjects (i.e., Mandarin Chinese, English, mathematics, and many others) by multiple teaching manpower for the purpose of improving students' academic achievements. Moreover, its types include not only free (or inexpensive) classes of after-school tutoring held by schools, teachers, and NGOs, but also the much more expensive off-campus private supplementary tutoring.

Attending after-school learning (including private supplementary tutoring and after-school tutoring) may cost a lot of time and moneys; however, whether it is useful in improving students' academic achievements is still in question. In order to provide evidence and support for the disadvantaged students in attending these additional learning activities, empirical findings are needed. In light of these issues, the current study shall seek to determine the effectiveness of after-school learning in improving disadvantaged students' academic achievement. Since most of disadvantaged students face the problems of poor families and lack of educational resources, there are some basic issues that need further discussions; such as whether their self-efficacies (e.g., the determination of facing challenges, self-confidence, and many others) are lower in comparison to the general peers? How about the relationship between self-efficacy and academic achievement? Can self-efficacy be generated after attending after-school learning? In the past, it is quite hard to get a large number of samples of disadvantaged students. However, since the establishment of the "Taiwan Database of Children and Youth in Poverty", opportunities in understanding the relationship between after-school learning, self-efficacy, and academic achievement for disadvantaged middle school students within the quantitative viewpoint is made available; moreover, in depth analysis of the relationships of these three variables can also be accomplish.

\subsection{After-school learning in Taiwan}

The "educational priority areas project" is carried out by the Ministry of Education of Taiwan since 1996, "academic tutoring" is one of the subsidies in this project. The subsidy objects include elementary schools and middle schools in offshore islands or regions with higher rates of aboriginal students; moreover, the subjects of after-school tutoring include Mandarin Chinese, mathematics, social studies, science and technology (Ministry of Education, Taiwan, 2011a). In addition, there is another project called the "hand-in-hand project" carried out in Taiwan since 2005, it offers free after-school tutoring during after-class hours for the students with disadvantaged identities and poor academic achievements; moreover, the subjects include Mandarin Chinese, English, mathematics, social studies, science and technology (Hsu \& Liu, 2015; Ministry of Education, Taiwan, 2011b). However, these two projects are now combined into the "project for the implementation of remedial instruction in primary and secondary schools"; furthermore, the objective for this integrated project are expended to all the students with poor academic achievements and the subjects focus on Mandarin Chinese, English, and mathematics (Ministry of Education, Taiwan, 2011b).

In addition, some NGOs have tried to hold classes in after-school tutoring for disadvantaged children, such as Boyo Social Welfare Foundation (2011) which offers free after-school tutoring services for children of disadvantaged families. The Taiwan Fund for Children and Families [TFCF] (2017), carries out the project of college students participating in academic tutoring and the project of learning promotion, which subsidize economically disadvantaged children in attending private supplementary tutoring or after-school care centers, and so on. Besides, according to the results of 2001 Taiwan Education Panel Survey [TEPS], the percentage of general middle school students attending private supplementary tutoring had reached $72.4 \%$ (Liu, 2006). However, although profit seeking is very important for private supplementary tutoring in general. Since 2011, the National Association of Continuing Education of Taiwan (2018) have carried out the "project of fostering seedlings" and offered a lot of free (or inexpensive) enrollment quota for disadvantaged students.

As mentioned above, the governments and NGOs in Taiwan have put more and more educational resources into offering opportunities of after-school learning for disadvantaged students in recent twenty years so that the 
learning difficulties of these students can be improved.

\subsection{The relationships between after-school learning, self-efficacy, and academic achievement}

With regards to the relationships between after-school learning, self-efficacy, and academic achievement, there are some preliminary discussions as follows:

First, the relationship between after-school learning and academic achievement is reviewed. There are some different definitions about "academic achievement". Chen (2011) noted that academic achievement is the ranks of mean academic grades of compulsory subjects within the various mixed courses. In addition, Yeh (2009) also noted that poor achievement students can be defined as the students who failed a subject and their academic performance lower than other students by performance evaluation. According to above viewpoints, "academic achievement" is defined as the students' comprehensive performance of passing subjects and getting achievement rankings in this study. With regards to the relationship between after-school learning (including private supplementary tutoring and after-school tutoring) and academic achievement, Liu (2006) indicated the weekly hours of private supplementary tutoring is a significant predictor separately on comprehensive analytical ability $(\beta=.290, p<.05)$ and mathematical analytical ability $(\beta=.319, p<.05)$ for middle school students. Moreover, Rothman and Henderson (2011) also found that the standardized test scores in language arts and mathematics of the eighth grade students who attended after-school tutoring program (experimental group) are significantly better than the ones who didn't attend (control group). However, there are different findings in other studies. For examples, Orman (2016) indicated the period of attending after-school tutoring program had no significant effect on the students' academic achievements (including English, reading and mathematics); moreover, the study of Kuan and Lee (2008) also showed that attending mathematics private supplementary tutoring has better mean treatment effect on mathematical performance only for the students with poor prior mathematical ability or whose parents have lower educational levels; otherwise, the effect of private supplementary tutoring is limited. As a result, whether attending private supplementary tutoring and after-school tutoring is able to improve the students' academic achievements is uncertain, it seems to depend on the actual circumstances of each individual cases.

Second, the relationship between after-school learning and self-efficacy is discussed. "Self-efficacy" is the belief in one's own ability to successfully accomplish something and achieve a goal; furthermore, people with a strong sense of efficacy believe they can accomplish even difficult tasks (Bandura, 1994). In addition, Feng and Lee (2010) interpreted that self-efficacy means a person's viewpoint of the abilities of working performance on himself; moreover, the efficacy expectation will influence one's abilities, degree of effort, perseverance with facing difficulties. To sum up, self-efficacy means a belief that people believe in themselves, that they can achieve goals or accomplish difficult tasks; i.e., it's an attitude that one person has confidence in overcoming difficulties, dealing with problems and not being afraid of opposition. With regard to the relationship between after-school learning and self-efficacy, in the result of meta-analysis of Durlak, Weissberg, and Pachan (2010), it was found that after-school programs have significant mean effects $(\mathrm{SMD}=.34, p<.05)$ on improving students' self-concepts (e.g., increasing confidences and self-esteems). Moreover, LeCroy (2004) carried out an experimental study of the after-school program called "Go Grrrls", it was showed that the students' self-efficacies in experimental group who attended this program have been improved significantly (i.e., the scores of post-test is higher than pre-test); furthermore, the self-efficacies of experimental group are significantly higher than control group who didn't attend this program. Nevertheless, Hirsch, Hedges, Stawicki, and Mekinda (2011) found that the difference between pre-test and post-test of self-efficacies is not significant for high school students who attended after-school programs (experimental group) and students who didn't attend after-school programs (control group). Furthermore, Niehaus, Rudasill and Adelson (2012) also indicated that middle school students' scores of self-efficacies had no significant change after attending after-school programs. Therefore, whether attending private supplementary tutoring and after-school tutoring can improve students' self-efficacies, it may not be the same in different cases? 
Could disadvantaged students' achievements be improved through after-school learning \& self-efficacy?

Third, with regard to the relationship between self-efficacy and academic achievement, Motlagh, Amrai, Yazdani, Abderahim and Souri (2011) indicated that among all the sub-factors of self-efficacy, only self-evaluation $(\beta=.388, p<.01)$ and self-regulation $(\beta=.352, p<.01)$ are significant predictors on academic achievement; moreover, they can explain $10.8 \%$ of total variance. Furthermore, Ogunmakin and Akomolafe (2013) also found that the academic self-efficacy of secondary school students in Ondo state is a significant predicator on academic performance $(\beta=.41, p<.05)$. However, Niehaus et al. (2012) found that after controlling the prior academic achievement (pre-test) of middle school students, self-efficacy is not a significant predicator on reading achievement (post-test). To sum up, although many studies support self-efficacy is helpful for improving academic achievement; however, there is a counterexample found in other study.

In conclusion, since economically disadvantaged students are underprivileged groups relative to the general student population, whether after-school learning and self-efficacy can improve their academic achievements still needs further discussion.

\section{Method}

\subsection{Participants}

The samples used in this paper derive from "Taiwan Database of Children and Youth in Poverty: The Panel Study in 2013" (TDCYP) which were released on October 29, 2014. The population of this database include children, juveniles and families who got assistances from Taiwan Fund for Children and Families (TFCF), such as students of 4th - 6th grades in primary schools, and teenagers in middle schools through universities. The data in this database came from questionnaire surveys and interviews which were conducted from July 1 to December 31, 2013 (Taiwan Fund for Children and Families [TFCF], 2014a, 2014b). There are 968 samples of middle school disadvantaged students in this database analyzed for examining whether after-school learning and self-efficacy are helpful for improving disadvantaged students' academic achievements. The missing data are conducted by listwise deletion in this study. Among the aforementioned 968 samples, there are 485 "low-income households"(50.1\%), 121 "middle-low-income households"(12.5\%), 217 people who cannot get governmental subsidies but were specified as "poverty" by $\operatorname{TFCF}(22.4 \%)$, and 145 invalid samples who don't answer the question about qualifications of governmental subsidies(15.0\%). The criteria of "low-income household" and "middle-low-income household" differ with local governments in Taiwan; however, the criteria of Taipei City can be taken for example as Table 1.

\section{Table 1}

The 2013 criteria of "low-income household" and "middle-low-income household" in Taipei City

\begin{tabular}{lccc}
\hline \multicolumn{1}{c}{ Type } & $\begin{array}{c}\text { Average income } \\
\text { (per person per month) }\end{array}$ & $\begin{array}{c}\text { Movable property } \\
\text { (per person per year) }\end{array}$ & $\begin{array}{c}\text { Real estate } \\
\text { (per household) }\end{array}$ \\
\hline low-income household & $<$ NTD 14,794 & $\leqq$ NTD 150,000 & $\leqq$ NTD 6,550,000 \\
middle-low-income household & $<$ NTD 19,461 & $\leqq$ NTD 150,000 & $\leqq$ NTD 7,760,000 \\
\hline $\begin{array}{l}\text { Note. From Comprehensive social } \\
\text { https://slidesplayer.com/slide/11367494/ }\end{array}$ & welfare (pp. 34-35), by & Ministry of the Interior, Taiwan, 2013, retrieved from \\
\end{tabular}

\subsection{Research instrument and variables}

The $2^{\text {nd }}$ questionnaire for students of middle schools through universities in TDCYP is taken for a research instrument in this study. There are four aspects of "A. Your life", "B. Your families", "C. About you", and "D. Education and school life" in this questionnaire. According to related items in this questionnaire, the variables are organized as follows:

The aspect of "after school learning": In the issue D22 (i.e., which way of private supplementary tutoring or after-school tutoring do you attend in general) of the questionnaire, there are 6 dichotomous items as follows: 
(1)on-campus after-school tutoring (except for summer tutoring); (2)off-campus private supplementary tutoring (not free of charge); (3)off-campus free classes of after-school tutoring (held by communities, churches, TFCF, and so on); (4)the classes of after-school tutoring spontaneously held by school teachers (free of charge); (5)the classes of after-school tutoring spontaneously held by school teachers (not free of charge); (6)etc.. The above 6 items are also taken as 6 ways of after school learning in this study, and all their options are "Yes" (1) and "No" (0). The above 6 items are reorganized as two new variables for research purposes:

The circumstance of attending after-school learning: The above 6 dichotomous items are combined as a composite variable which is called the "extent of attending after-school learning". The composite variable is specified "1" if each of the above 6 dichotomous items is answered "Yes" (1); otherwise, it will be taken as "No" (0). Since "ordinal variable" is a variable with two or more categories, but the categories can also be ordered or ranked moving from greater to smaller values (or vice versa) (Foster, Diamond, \& Jefferies, 2014). Moreover, the circumstance of attending after-school learning can be ordered by the extent of attending after-school learning. Because when students answered "Yes" (1), their extent of attending after-school learning is higher than students who answered "No" (0). Therefore, the circumstance of attending after-school learning is specified as an ordinal variable. Since the "structural model" of structural equation modelling is an application of path analysis, and path analysis is a statistical technique for verifying the hypotheses among variables of the model by the statistical method of regression analysis, and presenting the results by path diagrams (Hwang, 2004). Furthermore, when multiple regression analysis is implemented, if a predicted variable (i.e., exogenous variable) is a nominal variable or ordinal variable, this variable should be transformed as a dummy variable (i.e., the code of answers should be transformed as " 0 " and " 1 " if the variable is a dichotomous item) for regression analysis (Chen, 2003). Consequently, the "extent of attending after-school learning" is transformed as a dummy variable for the analysis of structural equation modelling.

The type of after-school learning: The type of after-school learning is a new variable established for comparing the difference between "private supplementary tutoring" and "after-school tutoring". Moreover, the type of after-school learning can be analyzed using the "test of homogeneity" which is one method of chi-square tests.

The type of after-school learning is reorganized from the original data of above 6 ways of after school learning; moreover, it can be distinguished as 4 types:

$>$ Attending both private supplementary tutoring and after-school tutoring: This type means the students attend at least one of these five ways of after-school learning, including "on-campus after-school tutoring", "the classes of after-school tutoring spontaneously held by school teachers (free of charge)", "the classes of after-school tutoring spontaneously held by school teachers (not free of charge)", "off-campus free classes of after-school tutoring", and "etc."; furthermore, the students also attend "off-campus private supplementary tutoring (not free of charge)".

$>$ Only attending private supplementary tutoring: This type means the students who only attend "off-campus private supplementary tutoring (not free of charge)", but he/she don't attend each of other 5 ways of after-school learning (i.e., these ways belong to after-school tutoring).

$>$ Only attending after-school tutoring: This type means the students who attend at least one of these five ways of after-school learning, including "on-campus after-school tutoring", "the classes of after-school tutoring spontaneously held by school teachers (free of charge)", "the classes of after-school tutoring spontaneously held by school teachers (not free of charge)", "off-campus free classes of after-school tutoring", and "etc."; however, these students don't attend "off-campus private supplementary tutoring (not free of charge)".

$>\quad$ Non-attendance for after-school learning: This type means the students who don't attend any way of after-school learning. 
Could disadvantaged students' achievements be improved through after-school learning \& self-efficacy?

The aspect of "self-efficacy": In the issue C9 of the questionnaire, there are 9 items as follows: (1) can always solve problems if I try my best to do; (2) I can get what I want even others have raised objections; (3It's easy for me to keep my ideals and achieve my goal; (4)I can handle unexpected circumstances with my wisdom; (5)I must be able to solve most difficulties if I make the necessary effort; (6) I can face difficulties calmly because I trust my ability to handle things; (7) I can usually find several solutions when facing a difficult problem; (8)I can usually figure out some ways to deal with troubles; (9) I can overcome difficulties no matter what happens. All the above items are 4-point Likert-type scale with four options, including "completely incorrect" (1), "partially correct" (2), "mostly correct" (3), and "completely correct" (4). Moreover, all the above items are ordinal variables.

The "entire self- efficacy" called in this paper is specified as follows:

$>$ In the analysis of structural equation modeling, the "entire self- efficacy" means a latent variable extracted by the above 9 items.

$>$ In the analysis of chi-square test, the "entire self- efficacy" means a composite variable which is a median calculated from the above 9 items.

The aspect of "academic achievement": There are two items in the questionnaire to represent "academic achievement". The first one is "D15. Have you ever failed important exams (e.g., midterm exams or final exams) in this semester?"; moreover, it belongs to a 4-point Likert-type scale which is reversely scored as four options included "always" (1), "often" (2), "seldom" (3), and "never" (4). This item is called "passing exams" which is an ordinal variable.

The second one is "D16. What's your class rank in important exams?"; moreover, it belongs to a 4-point Likert-type scale which is scored as four options, including "within the last ranks" (1), "below average" (2), "above average" (3), and "within the top ranks" (4). This item is called "achievement ranking" which is an ordinal variable.

The "entire academic achievement" called in this paper is specified as follows:

$>$ In the analysis of structural equation modeling, the "entire academic achievement" means a latent variable extracted by the above 9 items.

$>$ In the analysis of chi-square test, the "entire academic achievement" means a composite variable which is a median calculated from the above 2 items.

\subsection{Research Design}

Two statistical software of SPSS 20.0 and LISREL 8.80 are used for analysis as follows:

Frequency distribution and percentage: The number and proportion of disadvantaged middle school students attending each type of after-school learning (including private supplementary tutoring and after-school tutoring) are explained by frequency distribution and percentage.

Structural equation modeling: The relationships among "after-school learning", "self-efficacy" and "academic achievement" of disadvantaged students are verified by structural equation modeling. Since all the variables are ordinal variables, the "polychoric correlation matrix" and "asymptotic covariance matrix" are calculated from raw data of TDCYP; moreover, these matrixes are applied for the analysis of structural equation modeling (Yu, 2006). Furthermore, the method of generally weighted least squares (WLS) is used for estimating parameter and assessing model fit. The relationships among above three main variables can be assumed as follows:

I . The symbols, contents and properties of related variables such as "after-school learning", "self-efficacy", 
Chang, I. H., Chin, J. M.-C., Ching, G. S., \& Chuang, C.-P.

and "academic achievement" are presented as Table 2.

\section{Table 2}

A list of related variables including "after-school learning", "self-efficacy" and "academic achievement"

\begin{tabular}{|c|c|c|c|}
\hline Symbol & Abbreviation & Content & Property \\
\hline $\mathrm{X}_{1}$ & after-school learning & The circumstance of attending after-school learning & Exogenous observed variable \\
\hline$\eta_{1}$ & self-efficacy & The aspect of "self-efficacy" & Endogenous latent variable \\
\hline$Y_{1}$ & & I can always solve problems if I try my best to do & Endogenous observed variable \\
\hline $\mathrm{Y}_{2}$ & & $\begin{array}{l}\text { I can get what I want even others have raised } \\
\text { objections }\end{array}$ & Endogenous observed variable \\
\hline $\mathrm{Y}_{3}$ & & $\begin{array}{l}\text { It's easy for me to keep my ideals and achieve my } \\
\text { goal }\end{array}$ & Endogenous observed variable \\
\hline $\mathrm{Y}_{4}$ & & $\begin{array}{l}\text { I can handle unexpected circumstances with my } \\
\text { wisdom }\end{array}$ & Endogenous observed variable \\
\hline $\mathrm{Y}_{5}$ & & $\begin{array}{l}\text { I must be able to solve most difficulties if I make } \\
\text { the necessary effort }\end{array}$ & Endogenous observed variable \\
\hline $\mathrm{Y}_{6}$ & & $\begin{array}{l}\text { I can face difficulties calmly because I trust my } \\
\text { ability to handle things }\end{array}$ & Endogenous observed variable \\
\hline $\mathrm{Y}_{7}$ & & $\begin{array}{l}\text { I can usually find several solutions when facing a } \\
\text { difficult problem }\end{array}$ & Endogenous observed variable \\
\hline $\mathrm{Y}_{8}$ & & $\begin{array}{l}\text { I can usually figure out some ways to deal with } \\
\text { troubles }\end{array}$ & Endogenous observed variable \\
\hline $\mathrm{Y}_{9}$ & & I can overcome difficulties no matter what happens & Endogenous observed variable \\
\hline$\eta_{2}$ & academic achievement & The aspect of "academic achievement" & Endogenous latent variable \\
\hline $\mathrm{Y}_{10}$ & & $\begin{array}{l}\text { Have you ever failed important exams (i.e., } \\
\text { midterm exams or final exams) in this semester? }\end{array}$ & Endogenous observed variable \\
\hline $\mathrm{Y}_{11}$ & & What's your class rank in important exams & Endogenous observed variable \\
\hline
\end{tabular}

ПI. A conceptual model of relationships among "after-school learning", "self-efficacy" and "academic achievement" for disadvantaged middle school students is specified as figure 1. Furthermore, the relationships of all variables in that model are specified as follows:

$>\quad$ The exogenous observed variable "after-school learning" $\left(X_{1}\right)$ is a predictor on both "self-efficacy" $\left(\eta_{1}\right)$ and "academic achievement" $\left(\eta_{2}\right)$ which are endogenous latent variables; moreover, their regression coefficients are $\gamma_{1}$ and $\gamma_{2}$ separately. Besides, "self-efficacy" $\left(\eta_{1}\right)$ is also a predictor on "academic achievement" $\left(\eta_{2}\right)$.

$>\quad$ The endogenous latent variable "self-efficacy" $\left(\eta_{1}\right)$ is extracted from 9 endogenous observed variables (i.e., $\mathrm{Y}_{1}$ to $\mathrm{Y}_{9}$ ). Their factor loadings are $\lambda_{\mathrm{Y} 1}$ to $\lambda_{\mathrm{Y} 9}$, and their measure errors are $\varepsilon_{1}$ to $\varepsilon_{9}$.

$>$ The endogenous latent variable "academic achievement" $\left(\eta_{2}\right)$ is extracted from two endogenous observed variables (i.e., $\mathrm{Y}_{10}$ and $\mathrm{Y}_{11}$ ). Their factor loadings are $\lambda_{\mathrm{Y} 10}$ to $\lambda_{\mathrm{Y} 11}$, and their measure errors are $\varepsilon_{10}$ to $\varepsilon_{11}$.

III. Chi-square test: There are four types of after-school learning, including "attending both private supplementary tutoring and after-school tutoring", "only attending private supplementary tutoring", "only attending after-school tutoring" and "non-attendance for after-school learning". Additionally, one of the chi-square tests which is called "test of homogeneity" is used for answering following questions: a. Do the percentages of disadvantaged middle school students with higher self-efficacy differ with the types of after-school learning? b. Do the percentages of disadvantaged middle school students with better academic achievement differ with the types of after-school learning? If there are significant differences in above test results, a comparing method of confidence interval created by Marascuilo and McSweeney (1977) is used for post hoc test. In the post hoc test, it means there is no significant difference between two types of after-school learning if the range of confidence interval $(\psi)$ includes 0 , and vice versa. Furthermore, a software called "EZChiSquare" designed by Tu (2010) can be used for this post hoc test. 
Figure 1. A conceptual model of relationships among "after-school learning", "self-efficacy" and "academic achievement" for disadvantaged middle school student

\section{Results}

\subsection{The circumstances of disadvantaged students attending after-school learning}

The numbers and proportions of Taiwanese disadvantaged middle school students attending each way of after-school learning is presented in Table 3. According to Table 3, most of these students are attending "on-campus after-school tutoring (except for summer tutoring)" which accounts for $28.8 \%$. Furthermore, the proportions of these students are decreased in the order of "off-campus private supplementary tutoring (not free of charge)" (22.9\%), "the classes of after-school tutoring spontaneously held by school teachers (free of charge)" (4.0\%), "off-campus free classes of after-school tutoring (holding by communities, churches, TFCF, and so on)" (3.7\%), "etc." (1.5\%), and "the classes of after-school tutoring spontaneously held by school teachers (not free of charge)" (0.6\%). The "etc." includes other learning ways such as night tutoring (for boarders), home tutoring, and so on. According to the report of 2001 Taiwan Education Panel Survey (TEPS), the proportion of Taiwanese middle school students generally attending private supplementary tutoring had reached $72.4 \%$ (Liu, 2006). It appeals that the percentage of disadvantaged middle school students attending private supplementary tutoring (22.9\%) in Taiwan is much lower than general students who have no special circumstances (72.4\%). The reason may be associated with $70.4 \%$ families of disadvantaged children and youth in Taiwan have difficulty in paying tuition fees for private supplementary tutoring (TFCF, 2014b). In addition, there are only 52.8\% disadvantaged middle school students attending after-school learning (including private supplementary tutoring and after-school tutoring). As for disadvantaged students who don't attend after-school learning, they account for $47.2 \%$ (see Table 3). It appeals that the proportion of attending after-school learning for disadvantaged students need to be enhanced.

Additionally, a variable called "types of after-school learning" has been reorganized as mentioned previously for comparing the difference of private supplementary tutoring and after-school tutoring. There are 4 options in this variable including "attending both private supplementary tutoring and after-school tutoring", "only attending private supplementary tutoring”, "only attending after-school tutoring", and "non-attendance for after-school learning"; the frequency distributions and percentages are presented as Table 4. 
Table 3

Frequency \& percentage of disadvantaged middle school students attending different ways of after-school learning

\begin{tabular}{|c|c|c|c|c|c|}
\hline \multirow{2}{*}{ Aspect / Item } & \multirow{2}{*}{$\begin{array}{c}\text { Valid } \\
\text { samples }\end{array}$} & \multicolumn{2}{|c|}{ Yes } & \multicolumn{2}{|c|}{ No } \\
\hline & & frequency & $\%$ & frequency & $\%$ \\
\hline $\begin{array}{l}\text { The aspect of "after-school learning" } \\
\text { (composite variable) }\end{array}$ & 964 & 509 & $52.8 \%$ & 455 & $47.2 \%$ \\
\hline $\begin{array}{l}\text { 1.off-campus private supplementary tutoring (not free of } \\
\text { charge) }\end{array}$ & 964 & 221 & $22.9 \%$ & 743 & $77.1 \%$ \\
\hline $\begin{array}{l}\text { 2.on-campus after-school tutoring (except for summer } \\
\text { tutoring) }\end{array}$ & 964 & 278 & $28.8 \%$ & 686 & $71.2 \%$ \\
\hline $\begin{array}{l}\text { 3.the classes of after-school tutoring spontaneously held } \\
\text { by school teachers (free of charge) }\end{array}$ & 964 & 39 & $4.0 \%$ & 925 & $96.0 \%$ \\
\hline $\begin{array}{l}\text { 4.the classes of after-school tutoring spontaneously held } \\
\text { by school teachers (not free of charge) }\end{array}$ & 964 & 6 & $0.6 \%$ & 958 & $99.4 \%$ \\
\hline $\begin{array}{l}\text { 5.off-campus free classes of after-school tutoring } \\
\text { (holding by communities, churches, TFCF, and so on) }\end{array}$ & 964 & 36 & $3.7 \%$ & 928 & $96.3 \%$ \\
\hline 6.etc. & 964 & 14 & $1.5 \%$ & 950 & $98.5 \%$ \\
\hline
\end{tabular}

\section{Table 4}

Frequency \& percentage of disadvantaged middle school students attending different types of after-school learning

\begin{tabular}{|c|c|c|c|}
\hline Types of after-school learning & & Frequency & $\%$ \\
\hline 1.attending both private supplementary tutoring and after-school tutoring & & 50 & $5.2 \%$ \\
\hline 2.only attending private supplementary tutoring & & 171 & $17.7 \%$ \\
\hline 3.only attending after-school tutoring & & 288 & $29.9 \%$ \\
\hline 4.non-attendance for after-school learning & & 455 & $47.2 \%$ \\
\hline & total & 964 & $100.0 \%$ \\
\hline
\end{tabular}

Note. There are 4 missing data.

According to Table 4, besides $47.2 \%$ disadvantaged middle school students are non-attendance for after-school learning, the type of after-school learning that most disadvantaged students attending is "only attending after-school tutoring" (29.9\%). The second is "only attending private supplementary tutoring" (17.7\%). Moreover, disadvantaged students who attend "both private supplementary tutoring and after-school tutoring" are the fewest.

\subsection{The analysis of structural equation modelling for relationships among “after-school learning”,}

"self-efficacy", and "academic achievement"

The relationships among "after-school learning", "self-efficacy", and "academic achievement" for disadvantaged middle school students can be analyzed by structural equation modelling as follows:

Parameter estimation and goodness-of-fit: The results of parameter estimation and goodness-of-fit in this model is presented as figure 2. According to figure 2, the relationships among "after-school learning", "self-efficacy", and "academic achievement" for disadvantaged middle school students can be explained as such.

According to the suggestion of Hwang (2004), the results of test of goodness-of-fit for above relationships among "after-school learning", "self-efficacy", and "academic achievement" are as follows: (1) The aspect of "absolute fit indices": GFI (Goodness of Fit Index) is .99 and AGFI (Adjusted Goodness of Fit Index) is .99, both above indices meet the fit standard of greater than .90. Moreover, RMSEA (Root Mean Square Error of Approximation) is .049 , it also meets the range of good fit (RMSEA $\leq .05$ ). It appeals that the consistency between the conceptual model and samples in this model is very well. (2) The aspect of "relative fit indices": NFI (Normed Fit Index) is .97, NNFI (Non-Normed Fit Index) is .97, CFI (Comparative Fit Index) is .98, IFI (Incremental Fit Index) is .98, and RFI (Relative Fit Index) is .96. All of above five indices meet the fit standard of greater than .90. Consequently, this model is much closer to perfect fit than other models. (3) The aspect of "parsimony fit indices": Since PGFI (Parsimony Goodness of Fit Index) is .66 and PNFI (Parsimony Normed Fit 
Index) is .76, both of them meet the fit standard of greater than .50; moreover, CN (Critical N) is 438.94 which meets the standard of greater than 200. Additionally, Model CAIC is 373.59, and it's less than Saturated CAIC (5738.21) and Independence CAIC (612.39). It appeals that this model can be presented by simple and valid concepts and relationships. As mentioned above, this model has reached well goodness-of-fit on the whole; moreover, this conceptual model can be verified by the samples in TDCYP.

Figure 2. The path diagram of the relationships among "after-school learning", "self-efficacy", and "academic achievement" for disadvantaged middle school students

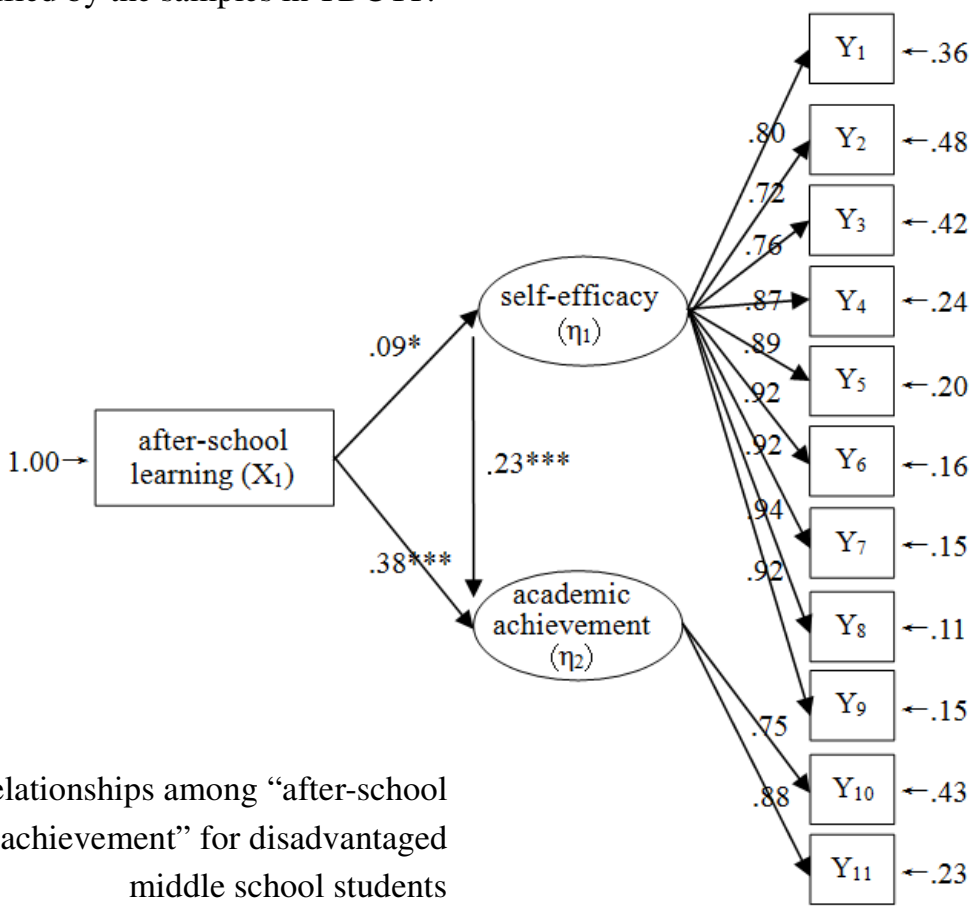

Note. GFI=.99, AGFI=.99, RMSEA=.049, NFI=.97, NNFI=.97, CFI=.98, IFI=.98, RFI=.96, PGFI=.66, PNFI=.76, CN=438.94, Model CAIC $=373.59$ (Independence CAIC=5738.21, Saturated CAIC=612.39).

As indicated in figure 2, the relationships among "after-school learning", "self-efficacy", and "academic achievement" for disadvantaged middle school students are as follows:

The relationship between "after-school learning” and "self-efficacy”: After-school learning is a significant predictor of self-efficacy $\left(\gamma_{1}=.09, p<.05\right)$; moreover, it belongs to a direct effect but its effect size is smaller. Although there are different conclusions about whether self-efficacy can be improved by after-school learning in past studies, it can be concluded in this study that disadvantaged students' self-efficacies can be improved slightly by attending after-school learning. The result as mentioned above corresponds with the studies of Durlak et al. (2010), LeCroy (2004), etc.

The relationship between "after-school learning” and "academic achievement": After-school learning is a significant predictor of academic achievement $\left(\gamma_{2}=.38, p<.001\right)$ which brings a direct effect; moreover, after-school learning can also make predictions indirectly on academic achievement through self-efficacy $(.09 * .23=.02, p<.05)$. Therefore, the total effect of after-school learning on academic achievement is .40 $(=.38+.02)$. In other words, disadvantaged students' academic achievements can be improved moderately by attending after-school learning. Meanwhile, through the mediator of self-efficacy, after-school learning can also indirectly improve disadvantaged students' academic achievements slightly. The result as mentioned above corresponds with the studies of Liu (2006), Rothman and Henderson (2011), Durlak et al. (2010), etc.

The relationship between "self-efficacy" and "academic achievement": Self-efficacy is a significant predictor of academic achievement $\left(\beta_{1}=.23, p<.001\right)$; moreover, it belongs to a direct effect but its effect size is smaller. In other words, the academic achievement can be improved slightly when disadvantaged students' self-efficacies are higher. The result as mentioned above correspond with the studies of Motlagh et al. (2011), Ogunmakin and Akomolafe (2013), Doménech-Betoret, Abellán-Roselló, and Gómez-Artiga (2017), etc. 


\section{Analysis of reliability:}

$>\quad$ Reliability of individual observed variable: The reliabilities of individual observed variable $\left(\mathrm{R}^{2}\right)$ for the 11 endogenous observed variables in this model are as follows: $\mathrm{Y}_{1}(.64), \mathrm{Y}_{2}(.52), \mathrm{Y}_{3}(.58), \mathrm{Y}_{4}(.76)$, $\mathrm{Y}_{5}(.80), \mathrm{Y}_{6}(.84), \mathrm{Y}_{7}(.85), \mathrm{Y}_{8}(.89), \mathrm{Y}_{9}(.85), \mathrm{Y}_{10}(.57), \mathrm{Y}_{11}(.77)$. Above values of $\mathrm{R}^{2}$ are up to the standard of greater than .50 which is suggested by Bagozzi and Yi (1988). Therefore, the reliabilities of individual observed variable in this model are very well.

$>$ Composite reliability of latent variables: The formula for calculating composite reliability of latent variables is as follow: $\rho_{\mathrm{c}}=(\Sigma \lambda)^{2} /\left[(\Sigma \lambda)^{2}+\Sigma(\theta)\right]$ (Hwang, 2004). In this model, $\rho_{\mathrm{c}}$ of "self-efficacy" is .963 , and $\rho_{\mathrm{c}}$ of "academic achievement" is .801. All of above latent variables are up to the standard of $\rho_{c}>.60$ which is presented by Bagozzi and Yi (1988). To sum up, the composite reliabilities in this model are very well, too.

\section{Analysis of validity:}

$>$ The formula for calculating average variance extracted (AVE) of latent variables is as follow: $\rho_{\mathrm{v}}=$ $\left(\Sigma \lambda^{2}\right) /\left[\Sigma \lambda^{2}+\Sigma(\theta)\right]$ (Hwang, 2004). In this model, $\rho_{\mathrm{v}}$ of "self-efficacy" is .747, and $\rho_{\mathrm{v}}$ of "academic achievement" is .669. All of above latent variables are up to the standard of $\rho_{\mathrm{v}}>.50$ which is presented by Bagozzi and Yi (1988). In conclusion, it's verified that the convergent validity in this model is good. In other words, all the observed variables contribute to the latent variables in this model are greater than errors.

\subsection{The difference of self-efficacies and academic achievements between different types of after-school learning}

for disadvantaged students

In order to understand whether self-efficacies and academic achievements differ with the type of after-school learning for disadvantaged students, the "test of homogeneity" of chi-square tests is used for following analysis. Furthermore, the type of after-school learning includes "attending both private supplementary tutoring and after-school tutoring", "only attending private supplementary tutoring", "only attending after-school tutoring", and "non-attendance for after-school learning".

The test of homogeneity for disadvantaged students with higher "self-efficacies" between different types of after-school learning - The results of test of homogeneity for disadvantaged students with higher "self-efficacies" between different types of after-school learning are presented in Table 5. The "self-efficacy" is a median computed from $\mathrm{Y}_{1}$ to $\mathrm{Y}_{9}$, and it's a measure of central tendency of ordinal variable. The self-efficacy is specified as "higher" if the median is 2.5 and above; moreover, the self-efficacy is specified as "lower" if the median is less than 2.5. There is a further explanation as follows: Since above 9 items ( $\mathrm{Y}_{1}$ to $\mathrm{Y}_{9}$ ) belong to 4-points Likert scale, the medians may be 1.5, 2.5 or 3.5 when there are even number of items (e.g., there are odd number of items with missing data in above 9 items).

\section{Table 5}

Test of homogeneity for students with higher "self-efficacies" between different types of after-school learning

\begin{tabular}{|c|c|c|c|c|c|c|c|c|c|c|c|c|c|}
\hline Type & & 1 & & 2 & & 3 & & 4 & Sum & & & & Post \\
\hline $\begin{array}{c}\text { Self- } \\
\text { efficacy }\end{array}$ & $n$ & $\%$ & $n$ & $\%$ & $n$ & $\%$ & $n$ & $\%$ & $\begin{array}{c}\text { Cumulative } \\
\text { Freq }\end{array}$ & $\begin{array}{c}\text { Total } \\
\%\end{array}$ & $\chi^{2}$ & $p$ & $\begin{array}{l}\text { hoc } \\
\text { test }\end{array}$ \\
\hline Higher & 27 & $54.0 \%$ & 78 & $45.9 \%$ & 117 & $40.6 \%$ & 165 & $36.3 \%$ & 387 & $40.2 \%$ & 9.199 & .027 & - \\
\hline Lower & 23 & $46.0 \%$ & 92 & $54.1 \%$ & 171 & $59.4 \%$ & 290 & $63.7 \%$ & 576 & $59.8 \%$ & & & \\
\hline
\end{tabular}

Note. 1.Type 1 is "Attending both private supplementary tutoring and after-school tutoring", type 2 is "Only attending private supplementary tutoring", type 3 is "Only attending after-school tutoring", and type 4 is "Non-attendance for after-school learning". 2.There are 5 missing data not including in this table. "Freq" means frequency. "Within \%" means the percentage of within group.

According to Table 5, the disadvantaged students with "higher" self-efficacies account for $40.2 \%$ on the whole; moreover, the ones with "lower" self-efficacies account for 59.8\%. It appeals that most of disadvantaged 
middle school students have lower self-efficacies. The value of $\chi^{2}$ is $9.199(p=.027)$, and it has reached statistical significance $(p<.05)$. Nevertheless, after carrying out the rigorous post hoc test presented by Marascuilo and McSweeney (1977), the ranges of confidence interval $(\psi)$ in each paired comparison all include 0; i.e., the percentages of disadvantaged students with "higher" self-efficacies have no significant differences between each paired comparison of the types of after-school learning.

The test of homogeneity for disadvantaged students with better "academic achievement" between different types of after-school learning - The results of test of homogeneity for disadvantaged students with better "academic achievement" between different types of after-school learning are presented in Table 6. The "academic achievement" is a median computed from $\mathrm{Y}_{10}$ to $\mathrm{Y}_{11}$, and it's a measure of central tendency of ordinal variable. The academic achievement is specified as "better" if the median is 2.5 and above; moreover, the academic achievement is specified as "poorer" if the median is less than 2.5 .

\section{Table 6}

Test of homogeneity for students with better "academic achievement" between different types of after-school learning

\begin{tabular}{|c|c|c|c|c|c|c|c|c|c|c|c|c|c|}
\hline Types & & 1 & & 2 & & 3 & & 4 & Sun & & & & Post \\
\hline $\begin{array}{c}\text { Academic } \\
\text { achievement }\end{array}$ & $n$ & $\%$ & $n$ & $\%$ & $n$ & $\%$ & $n$ & $\%$ & $\begin{array}{c}\text { Cumulative } \\
\text { freq }\end{array}$ & $\begin{array}{c}\text { Total } \\
\%\end{array}$ & $\chi^{2}$ & $p$ & $\begin{array}{l}\text { hoc } \\
\text { test }\end{array}$ \\
\hline Better & 35 & $71.4 \%$ & 139 & $81.8 \%$ & 157 & $54.5 \%$ & 195 & $42.9 \%$ & 526 & $54.7 \%$ & 81.538 & $<.001$ & $\begin{array}{l}1>4 \\
2>3\end{array}$ \\
\hline Poorer & 14 & $28.6 \%$ & 31 & $18.2 \%$ & 131 & $45.5 \%$ & 260 & $57.1 \%$ & 436 & $45.3 \%$ & & & $\begin{array}{l}2>4 \\
3>4\end{array}$ \\
\hline
\end{tabular}

Note. 1.Type 1 is "Attending both private supplementary tutoring and after-school tutoring", type 2 is "Only attending private supplementary
tutoring", type 3 is "Only attending after-school tutoring", and type 4 is "Non-attendance for after-school learning". 2.There are 6 missing data not including in this table. "Freq" means frequency. "Within \%" means the percentage of within group.

According to Table 6, the disadvantaged students with "better" academic achievement for $54.7 \%$ on the whole; moreover, the ones with "poorer" academic achievement account for $45.3 \%$. Since there are nearly half of disadvantaged middle school students with poorer academic achievement, it appeals that many disadvantaged students' academic achievement need to be improved. The value of $\chi^{2}$ is $81.538(p<.001)$, and it has reached statistical significance $(p<.05)$. It appeals that the percentages of disadvantaged students with better academic achievement will differ from the type of after-school learning. Furthermore, after carrying out the post hoc test presented by Marascuilo and McSweeney (1977), there are two findings as follows:

$>\quad$ In the percentages of disadvantaged students with better academic achievements, the ones who "attending both private supplementary tutoring and after-school tutoring" (71.4\%), "only attending private supplementary tutoring" $(81.8 \%)$ and "only attending after-school tutoring" (54.5\%) are significantly greater than "non-attendance for after-school learning" (42.9\%). In other words, attending private supplementary tutoring and after-school tutoring is helpful for increasing the percentage of disadvantaged students with better academic achievements.

$>\quad$ Furthermore, in the percentage of disadvantaged students with better academic achievements, the one who "only attending private supplementary tutoring" $(81.8 \%)$ are even significantly greater than "only attending after-school tutoring" (54.5\%). It appeals that the effectiveness of attending private supplementary tutoring is better than attending after-school tutoring.

\section{Discussion}

Economically disadvantaged students are usually the ones trapped at the bottom of the society and needed others to help them no matter in any countries/regions. However, the issues on how to help these disadvantaged students strive for success is always one of the most important educational issues. According to the current results, some important findings are as follows:

First, since the majority of disadvantaged middle school students in Taiwan have lower self-efficacies 
(59.8\%), it appears that most of the students relatively cannot keep their ideals, try their best to solve problems, deal with troubles, and trust themselves be able to handle things well, which are obstruction to their future success. The results of structural equation modelling also found that disadvantaged students' self-efficacies can be improved slightly $\left(\gamma_{1}=.09, p<.05\right)$ by attending after-school learning. However, within the chi-square tests, self-efficacies of disadvantaged students have no significant difference with the type of after-school learning.

Second, although most disadvantaged students are trapped in poverty, their academic achievements can improved slightly by enhancing their self-efficacies $\left(\beta_{1}=.23, p<.001\right)$. Since the predictive effect of self-efficacy on academic achievement is small, it appears that academic achievement is not improved by self-efficacy alone. These may be associated with most of the disadvantaged students having lower self-efficacies (59.8\%). Moreover, there seem to be other contributing factors resulting in the differences within academic achievement, which needs further discussion in future studies. Because the enhancement of self-efficacies is contributive to improvement of the academic achievements of disadvantaged students, the researchers suggest that the authorities should try to propose strategies for enhancing the self-efficacies of disadvantaged students. For instance, the authorities can encourage teachers to praise and recognize their students more often. This can be accomplished within teachers' workshops, give students more opportunity to read encouraging books, invite famous alumni or college students to share their successful experiences with these disadvantaged students. In essence, authorities are encouraged to take multiple strategies in enhancing disadvantaged students' self-confidences, thus broadening their horizons (i.e., their self-efficacies may be enhanced), so that their academic achievements may be improved to a certain extent. Third, after the disadvantaged students attended after-school learning, their academic achievements can be improved directly $\left(\gamma_{2}=.38, p<.001\right)$. Moreover, it can also improve their academic achievements indirectly through self-efficacies $(.09 * .23=.02, p<.05)$. As a whole, when disadvantaged students attends after-school learning, their academic achievements can be moderately improved (total effect=.40). In other words, the after-school learning activities held by governments and NGOs are helpful for improving disadvantaged students' academic achievements. However, the total effect of after-school learning on academic achievements is still quite limited. It appears that the causes of why disadvantaged students have poor academic achievements are very complicated, and current after-school learning activities are not enough to improve their academic achievements comprehensively. In other words, some existing practices of after-school learning activities (such as recruiting teachers, designing curriculums and choosing teaching materials) seemingly needs to be reviewed and improved. Besides, there seems to be some other factors (such as working part-time after school, bad learning environments) that contribute to the students' poor academic achievements. Fourth, even if there are many after-school learning activities held by the governments and NGOs in Taiwan, the percentage of disadvantaged middle school students who do not attend after-school learning (including private supplementary tutoring and after-school tutoring) in normal times is still up to $47.2 \%$. Moreover, the percentage of disadvantaged students who are able to attend private supplementary tutoring is only $22.9 \%$, which is significantly lower than the percentage of general middle school students (whose percentage has been up to $72.4 \%$ in 2001) who attended private supplementary tutoring. In addition, almost $70.4 \%$ of the families of disadvantaged children and youths have difficulty paying for private supplementary tutoring. It follows that there are still many disadvantaged students who are unable to attend after-school learning; hence, they need additional educational resources and supports from both the governments and NGOs.

Furthermore, around $45.3 \%$ of the disadvantaged students are having poor academic achievements. That is, nearly half of them often fail in important exams (e.g., midterm exams or final exams), and their ranks in classes are often below average. In other words, these disadvantaged students are not only trap in poverty, but nearly half of them cannot even catch up with the general students' academic achievements. It would seem that many disadvantaged students have to face financial and academic problems simultaneously, hence, trapped in the vicious circle of social reproduction. Therefore, disadvantaged students really need others to help them.

With the above finding, the current study confirmed that disadvantaged students' academic achievements could be moderately improved by attending after-school learning. In addition, the researchers also suggest that 
the governments should provide strategies to solve these problems. For instance, the governments can give disadvantaged students vouchers for after-school learning so as to help them pay for their further remedial lessons. The governments can also subsidize schools to expand free classes of after-school tutoring; schools can also collaborate with NGOs or college student clubs and organize free remedial lessons for students. With these consolidated efforts, it is hoped that disadvantaged students' academic achievements will be improved gradually.

Finally, it is found that the disadvantaged students who have been attending private supplementary tutoring, after-school tutoring, or both end up having significantly higher academic achievements than the ones who do not attend any after-school learning. Moreover, further analysis shows that the percentage for disadvantaged students who has better academic achievements are those who "only attend private supplementary tutoring" (81.8\%), which is significantly higher than the ones who "only attend after-school tutoring" (54.5\%). It appears that in all types of after-school learning, the effectiveness of attending private supplementary tutoring is better than attending after-school tutoring. Therefore, it would be helpful for NGOs to subsidize disadvantaged students to attend private supplementary tutoring in areas where there is a shortage of educational resources. Furthermore, some institutes of private supplementary tutoring also give free quotas for disadvantaged students.

\section{Conclusion}

The main findings of this paper can be concluded as follows: (1) nearly half of these disadvantaged students do not attend after-school learning, while their academic achievements are poorer; (2) majority of these students have lower self-efficacies, however their self-efficacies is slightly enhanced by after-school learning; (3) the higher the students' self-efficacies are, the slightly better their academic achievements will be; (4) attending after-school learning seems to have a direct effect on the slight improvement towards the students' academic achievements, furthermore, attending after-school learning can also indirectly affect the slight improvement of students' academic achievements through self-efficacies; and (5) among the different types of after-school learning, private supplementary tutoring is more effective than after-school tutoring in helping disadvantaged students increase their percentage of better academic achievements.

To sum up, the researchers believed that it would be more effective to subsidize (funds can be from governmental budget and/or donations from NGOs) disadvantaged middle school students to attend private supplementary tutoring, since this is a much better option. Nonetheless, something can also be done for the disadvantaged students attending "on-campus after-school tutoring" (28.8\%), such as improving the quality of on-campus after-school tutoring services, establishing a mechanism to encourage excellent teachers in joining the on-campus after-school tutoring program (i.e., giving more rewards/incentives), hold professional workshops for teachers of after-school tutoring, and so on. Lastly, it is hope that the foregoing findings and suggestions are able to contribute to future policy improvements.

Acknowledgments: The data used in this study come from the plan of "Taiwan Database of Children and Youth in Poverty," which is funded by "Taiwan Fund for Children and Families". The data released by Survey Research Data Archive of Center for Survey Research, RCHSS, Academia Sinica. All of the authors appreciate the assistance from above governmental agency and members. However, the authors are responsible for contents of this study.

\section{References}

Bagozzi, R. P., \& Yi, Y. (1988). On the evaluation of structural equation models. Academic of Marketing Science, 16, 76-94. https://doi.org/10.1007/BF02723327

Bandura, A. (1994). Self-efficacy. In V. S. Ramachaudran (Ed.), Encyclopedia of human behavior (Vol. 4, pp. 71-81). New York: Academic Press.

Bowles, S., \& Gintis, H. (2002). Schooling in capitalist America revisited. Sociology of Education, 75(1), 1-18. 
Chang, I. H., Chin, J. M.-C., Ching, G. S., \& Chuang, C.-P.

https://doi.org/10.2307/3090251

Boyo Social Welfare Foundation. (2011). What are we doing. Retrieved from https://www.boyo.org.tw/boyo/about-boyo

Bray, M. (2013). Shadow education: Comparative perspectives on the expansion and implications of private supplementary tutoring. Procedia-Social and Behavioral Sciences, 77, 412-420. https://doi.org/10.1016/j.sbspro.2013.03.096

Byun, S., \& Baker, D. (2015). Shadow education. In R. Scott, S. Kosslyn, \& N. Pinkerton (Eds.), Emerging trends in the social and behavioral sciences: An interdisciplinary, searchable, and linkable resource (pp. 1-9). NY: Wiley-Blackwell. https://doi.org/10.1002/9781118900772.etrds0301

Chen, C.-C. (2003). Multiple regression analysis. In C. -C. Chen, B. -L. Cherng, S. -F Chen, \& T. -C. Liu (Eds.), Multivariate analysis methods: The application of statistical software (pp. 1-40). Taipei, Taiwan: Wunan.

Chen, C.-W. (2017). Relationship between after-school mathematics learning activities and mathematics learning achievements among Taiwanese students: An analysis of TIMSS 2003 data. Educational Review, 48 , 45-80.

Chen, H.-T. (2011). The students' properties and learning styles in integrated blended learning environment: A case study on college students of science and technology field. Journal of Education Research, 204, 56-71.

Chen, S.-L., Tzeng, S.-J., \& Chang, Y.-J. (2015). The comparison of the implementation and reading progress between two remedial programs on second grade students. Contemporary Educational Research Quarterly, 23(2), 35-74.

Doménech-Betoret, F., Abellán-Roselló, L., \& Gómez-Artiga, A. (2017). Self-efficacy, satisfaction, and academic achievement: The mediator role of students' expectancy-value beliefs. Frontiers in Psychology, 8(1193), 1-12. https://doi.org/10.3389/fpsyg.2017.01193

Durlak, J. A., Weissberg, R. P., \& Pachan, M. (2010). A meta-analysis of after-school programs that seek to promote personal and social skills in children and adolescents. American Journal of Community Psychology, 45, 294-309. https://doi.org/10.1007/s10464-010-9300-6

Feng, L.-C., \& Lee, I.-M. (2010). The influence of self-efficacy, and attributional style on creativity and academic performance of gifted elementary school students. Journal of Gifted Education, 10(2), 33-60.

Foster, L., Diamond, I., \& Jefferies, J. (2014). Beginning statistics: An introduction for social scientists. London: Sage Publications.

Hirsch, B. J., Hedges, L. V., Stawicki, J., \& Mekinda, M. A. (2011). After-school programs for high school students: An evaluation of after school matters. Technical Report. NY: Wallace Foundation.

Hong Kong Education Bureau. (2018). Ground rules and requirements for the school-based after-school learning and support programmes 2018/19 school year. Retrieved from https://www.edb.gov.hk/attachment/en/student-parents/support-subsidies/after-sch-learning-support-pr ogram/2018_19_Ground\%20Rules_English_clean.pdf

Hsu, W.-M., \& Liu, M.-L. (2015). Investigation on curriculum decision and instruction implementation of mathematics remedial instruction at after-school alternative program in elementary schools. Contemporary Educational Research Quarterly, 23(1), 113-147.

Hwang, F.-M (2004). Statistical methods for the social sciences: Structural equation modeling. Taipei, Taiwan: Wunan.

Kuan, P.-Y., \& Lee, D.-Y. (2008). Effects of cram schooling on math performance: A counterfactual analysis. Taiwanese Journal of Sociology, 41, 97-148.

LeCroy, C. W. (2004). Experimental evaluation of "Go Grrrls" preventive intervention for early adolescent girls. The Journal of Primary Prevention, 25(4), 457-473. https://doi.org/10.1023/B:JOPP.0000048112.10700.89

Legislative Council of Hong Kong. (2011). Provision of after-school learning support for students of low-income families. LC Paper No. CB (2)1986/10-11(04).

Li, M.-F., \& Lien, T.-C. (2010). A study of implementation process and results of the "Hand-in-hand project: 
Could disadvantaged students' achievements be improved through after-school learning \& self-efficacy?

Education support for disadvantaged child”. Journal of Educational Practice and Research, 23(1), 115-144.

Marascuilo, L. A., \& McSweeney, M. (1977). Nonparametric and distribution-free methods for the social sciences. Monterey, CA: Brooks/Cole Publishing Company.

Ministry of Education, Taiwan. (2000). Revised Mandarin Chinese Dictionary. Retrieved from https://english.moe.gov.tw/cp-34-14774-D022F-1.html

Ministry of Education, Taiwan. (2011a). 2012 Educational priority areas project. Promulgated by official letter (No.1000170771) of Ministry of Education on October 17, 2011.

Ministry of Education, Taiwan. (2011b). Project for the implementation of remedial instruction in primary and secondary schools. Approved by official letter (No.1000103358) of Executive Yuan on September 20, 2011.

Ministry of the Interior, Taiwan. (2013). Comprehensive social welfare. Retrieved from https://slidesplayer.com/slide/11367494/

Motlagh, S. E., Amrai, K., Yazdani, M. J., Abderahim, H. A., \& Souri, H. (2011). The relationship between self-efficacy and academic achievement in high school students. Procedia Social and Behavioral Sciences, 15, 765-768. https://doi.org/10.1016/j.sbspro.2011.03.180

National Association of Continuing Education of Taiwan. (2018). The project of fostering seedlings [Projects]. Retrieved from http://www.nacet.org.tw/nacet/Association/project.php

Niehaus, K., Rudasill, K. M., \& Adelson, J. L. (2012). Self-efficacy, intrinsic motivation, and academic outcomes among Latino middle school students participating in an after-school program. Hispanic Journal of Behavioral Sciences, 34(1), 118-136. https://doi.org/10.1177/0739986311424275

Liu, J. (2006). The transition, effect, and stratification of cram schooling in Taiwan. Bulletin of Educational Research, 52(4), 1-33.

Ogunmakin, A. O., \& Akomolafe, M. J. (2013). Academic self-efficacy, locus of control and academic performance of secondary school students in Ondo State, Nigeria. Mediterranean Journal of Social Sciences, 4(11), 570-576. https://doi.org/10.5901/mjss.2013.v4n11p570

Orman, H. E. (2016). The impact of expertise and after-school program dosage on at-risk student achievement (Unpublished doctoral dissertation). Bellarmine University, Kentucky.

Rothman, T., \& Henderson, M. (2011). Do school-based tutoring programs significantly improve student performance on standardized tests? Research in Middle Level Education Online, 34(6), 1-10. https://doi.org/10.1080/19404476.2011.11462079

Supplementary Education Act, Taiwan. $\$ 6$ (2017).

Taiwan Fund for Children and Families [TFCF]. (2014a). Taiwan database of children and youth in poverty: The panel study in 2013 (D00116) [data file]. Available from Survey Research Data Archive, Academia Sinica.

TFCF. (2014b). The report of Taiwan Database of Children and Youth in Poverty: The Panel Study in 2013. Taichung, Taiwan: Author.

TFCF. (2017). Financial aids for poor families. Retrieved from http://www.ccf.org.tw/36/page/net/server/server01.html

Yeh, Y.-M. (2009). The remedial instruction of mandarin for the children of marriage-immigrant females. Taipei, Taiwan: Showwe Information.

Yu, M.-N. (2006). Latent variable models: The application of SIMPLIS. Taipei, Taiwan: Higher education. 
Chang, I. H., Chin, J. M.-C., Ching, G. S., \& Chuang, C.-P. 